\title{
Reinforced Laryngeal Mask in Pediatric Laparoscopic Surgery
}

\author{
Xiao-Li Sun, Jie Li, Zhen-Yuan Wang, Ming-Ying Li, Wei Duan, Nan Wu and Ou Yang \\ Department of Anesthesiology, Beijing Chaoyang Hospital, Capital Medical University, Beijing 100043, China
}

\begin{abstract}
Objective: To determine the frequency of reflux and aspiration in children subjected to reinforced laryngeal mask during laparoscopic surgery in the Trendelenburg position, and evaluate its feasibility.

Study Design: A descriptive study.

Place and Duration of Study: Department of Anesthesiology, Beijing Chaoyang Hospital, Capital Medical University, from January 2017 to May 2018.

Methodology: A total of 300 children, who underwent laparoscopic high ligation of the hernial sac in the Trendelenburg position under general anesthesia, were enrolled into the present study. Reflux and aspiration were assessed by precise saliva $\mathrm{pH}$ to determine the $\mathrm{pH}$ value at laryngeal mask airway, and at sites on laryngeal mask corresponding to the larynx, face and peripheral area. Then, the presence of food residue was observed at various sites to determine whether there was reflux or aspiration during the operation.

Results: Suspected reflux (9.67\%) was observed in 29 children and suspected aspiration was observed in nine children $(3 \%)$. There was no definite reflux or aspiration observed in any of the children. Furthermore, the prevalence of suspected reflux was higher in children who were $>3$ years and overweight, compared to children with a normal body mass index and an age of $<3$ years.

Conclusion: With strict fasting and water deprivation, and strict selection of laryngeal mask indications before selective operation, it is feasible to apply reinforced laryngeal mask in laparoscopic surgery in the Trendelenburg position in children.
\end{abstract}

Key Words: Reinforced laryngeal mask, Trendelenburg position, Reflux, Aspiration, Children.

How to cite this article: Sun XL, Li J, Wang ZY, Li MY, Duan W, Wu N, Yang O. Reinforced laryngeal mask in pediatric laparoscopic surgery. J Coll Physicians Surg Pak 2019; 29(10):915-8.

\section{INTRODUCTION}

A child's protective reflexes are weaker with relatively greater amount of gastric juice. These factors induce high difficulty in respiratory management during an operation, making children prone to gastric or esophageal reflux. Therefore, the endotracheal anesthesia approach is often used in pediatric general anesthesia. However, problems continue to arise, such as difficulty in operating tracheal intubation and susceptibility to injury of the throat.1,2

Compared to endotracheal intubation, laryngeal mask has advantages of small cardiovascular stimulation, easy operation and low risk of airway managementrelated complications. ${ }^{3-5}$ However, it also has the risks of reflux, aspiration and upper respiratory tract infections during an operation.6-9 In particular, for children undergoing surgery in the Trendelenburg position (such as laparoscopic surgery of the lower abdominal organs), factors such as age, position and increased intra-

Correspondence to: Zhen-Yuan Wang, Department of Anesthesiology, Beijing Chaoyang Hospital, Capital Medical University, No. 5 Jingyuan Road, Shijingshan District, Beijing 100043, China

E-mail:wangzhenyuan1866@163.com

Received: July 10, 2018; Revised: January 03, 2019;

Accepted: July 04, 2019 abdominal pressure of the patient may increase the risk of reflux and aspiration during an operation. Therefore, the safety of the application of a laryngeal mask in the pediatric laparoscopic surgery in Trendelenburg position still needs to be studied, since there is a lack of evaluation and analysis of its safety.

The objective of this study was to evaluate the safety of application of laryngeal mask airway in laparoscopic surgery in the Trendelenburg position in children.

\section{METHODOLOGY}

This descriptive study was conducted at Department of Anesthesiology, Beijing Chaoyang Hospital, Capital Medical University, from January 2017 to May 2018. A total of 300 boys and girls aged 1-6 years, who underwent laparoscopic high ligation of the hernial sac in the Trendelenburg position under general anesthesia, were enrolled into the present study. The study was approved by the Ethics Committee of the hospital, and an informed consent was obtained from the guardians of children.

Keeping significance level $\alpha=0.05$, power of the test $(1-\beta)$, incidence of reflux esophagitis in general population $\mathrm{p} 0=0.02$, incidence of reflux in children undergoing general anesthesia $4-26.3 \%$, p1 was set as median, which was 0.1515 .

Based on the above parameters for calculation of the sample size, the minimum sample size in the present 
study was calculated, the result was $n=93$. In the present study, a total of 300 patients were analysed, which met the above sample size requirements. Exclusion criteria were: known pulmonary disease or airway abnormality, upper respiratory tract infection, potential risk of reflux and aspiration (a history of esophageal reflux, etc.), and oral inflammatory disease or dental caries. Obese children were also excluded.

Before the operation, the children were routinely deprived of solid food for eight hours, deprived of formula milk and fresh milk for six hours, and deprived of breast milk and clear liquid for four hours. Then, the children were transferred into the operation room, oxygen was given for de-nitrogen, and the inhalation flow of pure oxygen in the mask was set at $8-10 \mathrm{~L} / \mathrm{min}$. Children in early childhood, 1-3 years of age, and preschool children who could not cooperate were slowly injected with $1-3 \mathrm{mg} / \mathrm{Kg}$ of propofol by the anesthetist in anesthesia preparation room. Children were quickly transferred to the operating theatre closest to the anesthesia preparation room after the initial sedation. During transfer, the anesthesiologist accompanied the children in the entire process and a portable oxygen saturation monitor and a simple respiratory machine were carried. The children were successively and intravenously dripped with $0.1 \mu \mathrm{g} / \mathrm{Kg}$ of sufentanil citrate injection, $0.01 \mathrm{mg} / \mathrm{Kg}$ of atropine sulfate injection, and $0.1 \mathrm{mg} / \mathrm{Kg}$ of dexamethasone injection. After two minutes, a slow bolus injection of 2.5$4.0 \mathrm{mg} / \mathrm{Kg}$ of $1 \%$ propofol (medium- and long-chain fat emulsion injection, Fresenius Medical Care, containing $0.2 \%$ lidocaine) was given. After the disappearance of the eyelash reflex of the children, they received an intravenous bolus injection of $0.5 \mathrm{mg} / \mathrm{Kg}$ of rocuronium. After the mandible was relaxed, a reinforced laryngeal mask (Tianjin Meidisi Medical Supplies Co., Ltd.) was placed, and the model was determined according to the weight of the child. Success criteria for laryngeal mask placement were good, up and down movement of the aperture of the thorax, no gas leakage from the oropharynx, normal $\mathrm{PETCO}_{2}$ waveform, and peak airway pressure (Paw) in the normal range monitored by Drager anesthesia machine (Fabius Plus). The children were connected to a respirator to control their respiration. Intermittent positive pressure ventilation was given during the operation, respiratory rate $(R R)$ was controlled within 20-30/min, and end-tidal carbon dioxide $\left(\mathrm{PETCO}{ }_{2}\right)$ was maintained at $35-45 \mathrm{mmHg}$. Next, the children were intravenously injected with 4-10 $\mathrm{mg} /(\mathrm{Kg} \cdot \mathrm{h})$ of propofol and $0.1-0.2 \mu \mathrm{g} /(\mathrm{Kg} \cdot \mathrm{h})$ of remifentanil at a constant speed to maintain anesthesia, and were intravenously injected with $0.1 \mathrm{mg} / \mathrm{Kg}$ of rocuronium to maintain muscle relaxation, when necessary. During the operation, a suitable cuff was selected for each patient according to the age and weight, and the cuff pressure was monitored throughout the operation. The pressure of pneumoperitoneum was controlled under $10 \mathrm{mmHg}$ during the operation that was monitored by pneumoperitoneal machine. After the establishment of pneumoperitoneum, Trendelenburg position was slowly adjusted to $30^{\circ}$. At the end of the operation, the laryngeal mask was removed when spontaneous breathing rhythm was restored, and tidal volume (VT) reached $8 \mathrm{ml} / \mathrm{Kg}$. Then, precise saliva $\mathrm{pH}$ test strips were coated with attachments in the ventilation site of the laryngeal mask that corresponded to the larynx and face (mark 1, denoted as "pH mark 1"), laryngeal mask site that corresponded to the surrounding area of the larynx and face (mark 2, denoted as "pH mark 2"), and laryngeal mask site that corresponded to the tongue surface (mark 3 , denoted as "pH mark 3", Figure 1). The $\mathrm{pH}$ value of each sampling area was recorded after coating.

When $\mathrm{pH}$ mark 1 was $<6.6$, it was defined as suspected aspiration of children during the operation. When $\mathrm{pH}$ mark 1 was <6.6, pH mark 2 was $<6.6$, or $\mathrm{pH}$ mark 3 was $<6.6$, it was defined as suspected reflux of children during the operation. If food residue or gastric juice was found in the mark 1 area, it was defined as aspiration of children during the operation. If food residue or gastric juice was found in the mark 1 area or mark 3 area, it was defined as a reflux of children during the operation. BMI threshold was based on the BMI threshold of children aged 0 to 18 in China as the standard, and the overweight and obesity threshold of the US CDC and WHO was taken into account.

Data were statistically analysed using statistical software SPSS19.0. Quantitative data were expressed as mean \pm standard deviation $(x \pm S D)$. Counting data were expressed as percentages and compared using ChiSquare test. The logistic regression model was used to analyse related factors for reflux and aspiration. $\mathrm{P}<0.05$ was considered statistically significant.

\section{RESULTS}

The ages of these children ranged from 1-6 years. One hundred and fifty children were $<3$ years and the rest of children were $>3$ years (mean $=3.16 \pm 1.38$ years). Their body weight ranged from $10-30 \mathrm{~kg}$, mean $14.63 \pm 3.12$ $\mathrm{Kg}$. BMI of $261(87 \%)$ children was normal (mean 14.23 $\pm 2.64 \mathrm{~kg}$ ), with $39(13 \%)$ ranged in overweight (mean $17.34 \pm 4.53 \mathrm{~kg}$ ). The American Society of Anesthesiologists (ASA) grades of these children ranged within grade I-II. The mean pneumoperitoneum ventilation time on headdown position was $16.58 \pm 7.09$ minutes with mean total time of ventilation to laryngeal mask $40.50 \pm 6.34$ minutes.

Among the 300 children, 29 children (9.67\%) had suspected reflux, nine children (3\%) had suspected aspiration, and no definite reflux or aspiration was observed in any of the children. Factors that were correlated to the suspected reflux and aspiration observed in the 300 children were analysed using univariate non-conditional 
Table I: The results of univariate logistic regression analysis for suspected reflux and suspected aspiration.

\begin{tabular}{|c|c|c|c|c|c|c|c|c|c|c|c|c|}
\hline \multirow[t]{2}{*}{ Influence factor } & \multicolumn{6}{|c|}{ Suspected reflux } & \multicolumn{6}{|c|}{ Suspected aspiration } \\
\hline & $\mathrm{b}$ & SE & Wald $\chi^{2}$ & OR & $95 \% \mathrm{Cl}$ & $\mathrm{P}$ & $\mathrm{b}$ & SE & Wald $\chi^{2}$ & OR & $95 \% \mathrm{Cl}$ & $\mathrm{P}$ \\
\hline Age & 0.932 & 0.410 & 5.176 & 2.539 & $1.138-5.665$ & 0.023 & 1.494 & 0.810 & 3.401 & 4.457 & $0.910-21.822$ & 0.065 \\
\hline BMI & 1.082 & 0.457 & 5.596 & 2.949 & $1.204-7.226$ & 0.018 & 1.265 & 0.729 & 3.008 & 3.542 & $0.848-14.787$ & 0.083 \\
\hline $\begin{array}{l}\text { Pneumoperitoneum } \\
\text { ventilation time } \\
\text { on Trendelenburg } \\
\text { position }\end{array}$ & 0.270 & 0.049 & 30.781 & 1.310 & $1.191-1.441$ & $<0.01$ & 0.036 & 0.023 & 2.385 & 1.037 & $0.990-1.085$ & 0.122 \\
\hline $\begin{array}{l}\text { Total time of } \\
\text { ventilation to } \\
\text { laryngeal mask }\end{array}$ & 0.182 & 0.043 & 17.662 & 1.200 & $1.102-1.306$ & $<0.01$ & 0.024 & 0.030 & 0.612 & 1.024 & $0.965-1.087$ & 0.434 \\
\hline
\end{tabular}

Table II: Multivariate unconditional logistic regression analysis of suspected reflux.

\begin{tabular}{l|cccccc}
\hline Influence factor & $\mathrm{b}$ & $\mathrm{SE}$ & Wald $\chi^{2}$ & $\mathrm{OR}$ & $95 \% \mathrm{Cl}$ & $\mathrm{P}$ \\
\hline Age & 0.356 & 0.538 & 0.437 & 1.428 & $0.497-4.100$ & 0.508 \\
\hline BMI & 0.799 & 0.550 & 2.113 & 2.223 & $0.757-6.528$ & 0.146 \\
\hline $\begin{array}{l}\text { Pneumoperitoneum } \\
\text { ventilation time on }\end{array}$ & 0.224 & 0.065 & 11.927 & 1.251 & $1.102-1.420$ & 0.001 \\
$\begin{array}{l}\text { Trendelenburg position } \\
\begin{array}{l}\text { Total time of ventilation } \\
\text { to laryngeal mask }\end{array}\end{array}$ & 0.051 & 0.052 & 0.960 & 1.052 & $0.950-1.165$ & 0.327 \\
\hline
\end{tabular}

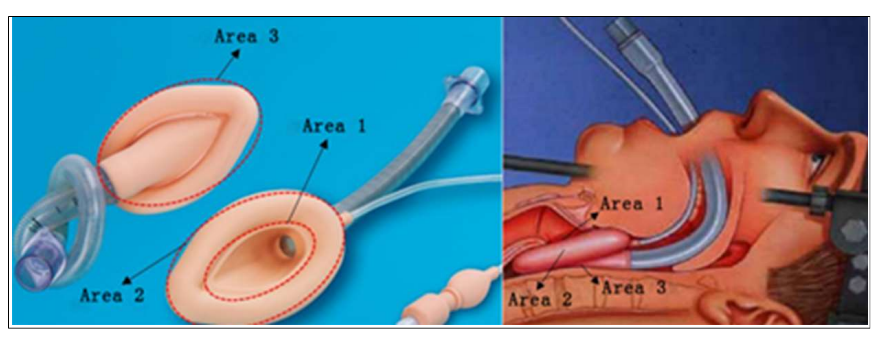

Figure 1: Sampling area sketch.

logistic regression analysis. The forced entry method (Enter) was used for calculation with a cardinality of $\alpha=0.05$. Age, body mass index (BMI), Trendelenburg position ventilation time and total laryngeal mask ventilation time were significantly associated with to the incidence of suspected reflux, but were not correlated to the incidence of suspected aspiration (Table I).

Based on the above-mentioned results of the univariate analysis, a multivariate non-conditional logistic regression analysis was performed for suspected reflux. Each factor with statistical significance in the univariate analysis $(p<0.05)$ was introduced into the regression model for the multivariate non-conditional logistic regression analysis. The multivariate non-conditional logistic regression analysis was carried out using backward stepwise elimination. Both univariate and multivariate analyses revealed that Trendelenburg position ventilation time was significantly and positively correlated with the incidence of suspected reflux (Table II).

Among these 300 children, a pH value in mark 1 or mark 2 of $<5.5$ was observed in three children. Among these three children, two children had a long ventilation duration in the Trendelenburg position, while one child had a high BMI (weight=29 kg, BMl=24.9).

\section{DISCUSSION}

Due to the advantages of less trauma, high safety and simplicity, shorter postoperative recovery time and less postoperative pain, laparoscopic surgery has been widely applied in clinic. In particular, pediatric laparoscopic surgery has become an important field in pediatric surgery. However, since laparoscopic surgery of the lower abdominal organs is usually performed in the Trendelenburg position, gravity factors and increased intra-abdominal pressure caused by surgical position may increase the incidence of reflux and aspiration. ${ }^{10}$ Reflux and aspiration are potential dangers in laryngeal mask ventilation. Therefore, the application of laryngeal masks during pediatric laparoscopic surgery in the Trendelenburg position remains controversial, and is a topic of concern. Although there are reports on the application of laryngeal masks in laparoscopic surgery in children, ${ }^{11-14}$ there is still a lack of relevant information on the safety assessment of its application during pediatric laparoscopic surgery in the Trendelenburg position. In order to better evaluate the $\mathrm{pH}$ values of the saliva and secretions at the sites on the laryngeal mask that corresponded to the face, periphery of face and lingua, the $\mathrm{pH}$ values at the laryngeal mask airway, and at sites on laryngeal mask that corresponded to the larynx, face and peripheral area, and the presence of food residue at various marked areas were observed in 300 children were determined. No definite reflux or aspiration occurred in any of the 300 children. The result is consistent with previous studies, indicating the good safety of using laryngeal mask in laparoscopic surgery. ${ }^{14}$ The intraoperative ventilation time of the Trendelenburg position was significantly correlated to reflux. The frequency of suspected reflux was higher in children who were $>3$ years and in overweight children, compared to children with normal BMI and an age of $<3$ years. The impact of the age was different from that reported by previous study. ${ }^{14}$ The reason for this result may be correlated to the sample size and case sampling, which needs further research.

Among these 300 children, a pH value in mark 1 or mark 2 of $<5.5$ was observed in three children. Among these three children, two children had a long ventilation time in 
the Trendelenburg position, while one child had a high $\mathrm{BMI}$. As indicated in previous studies, long ventilation time or high BMI was correlated with higher rate of complications. 10 Therefore, more attention should be given to the phenomenon that overweight and long operation time may increase the incidence of reflux. 10

Furthermore, care should be given when using laryngeal mask ventilation. In order to reduce stress reaction, fear and crying, for children in early childhood (1-3 years) and preschool children who cannot cooperate, child should be slowly injected with $1-3 \mathrm{mg} / \mathrm{Kg}$ of propofol by the anesthetist in anesthesia preparation room. During transfer, the anesthesiologist accompanied the children in the entire process and a portable oxygen saturation monitor and a simple respiratory machine were carried. In all children treated with the above operations, no accident occurred.

The biggest limitation of the current study is that there was no control group that received methods other than laryngeal mask. In the future, further studies may be carried out to evaluate the advantages of laryngeal mask over other methods.

\section{CONCLUSION}

Based on the analysis in the current study, it is considered feasible to apply reinforced laryngeal mask in laparoscopic surgery in the Trendelenburg position in children. More attention should be given to the phenomenon that overweight and long operation time may increase the incidence of reflux.

\section{ETHICAL APPROVAL:}

The ethical approval from Ethical Committee of Beijing Chao-Yang Hospital was obtained prior to initiation of the research work.

\section{PATIENTS' CONSENT:}

The informed consents have been obtained from patients to publish the data concerning this case.

\section{CONFLICT OF INTEREST:}

Authors declared no conflict of interest.

\section{AUTHORS' CONTRIBUTION:}

$X L S$ : Involved in drafting the manuscript and revising it critically for important intellectual content.

$\mathrm{JL}$ : Made substantial contributions to conception and design of the work.

MYL, WD, NW, OY: Made substantial contributions to the acquisition, analysis, and interpretation of data for the work.
ZYW: Participated in data interpretation and reviewed the manuscript; all authors given final approval of the version to be published.

\section{REFERENCES}

1. Fiadjoe JE, Nishisaki A, Jagannathan N, Hunyady AI, Greenberg RS, Reynolds PI, et al. Airway management complications in children with difficult tracheal intubation from the Pediatric Difficult Intubation (PeDI) registry: A prospective cohort analysis. Lancet Respir Med 2016; 4:37-48.

2. Yavascaoglu B, Tokat O, Basagan EM, Kaya FN, Erisen L, Kutlay $O$. The use of the laryngeal mask airway in children with subglottic stenosis. J Int Med Res 2001; 29:541-5.

3. Lopez-Gil M, Brimacombe J, Alvarez M. Safety and efficacy of the laryngeal mask airway: A prospective survey of 1400 children. Anaesthesia 1996; 51:969-72.

4. Huang AS, Hajduk J, Jagannathan N. Advances in supraglottic airway devices for the management of difficult airways in children. Expert Rev Med Devices 2015; 13:157-69.

5. Parikh SS, Parekh SB, Doshi C, Vyas V. Proseal laryngeal mask airway versus cuffed endotracheal tube for laparoscopic surgical procedures under general anesthesia: A random comparative study. Anesth Essays Res 2017; 11:958-63.

6. von Ungern-Sternberg BS, Boda K, Schwab C, Sims C, Johnson C, Habre W. Laryngeal mask airway is associated with an increased incidence of adverse respiratory events in children with recent upper respiratory tract infections. Anesthesiology 2007; 107:714-9.

7. Brimacombe J. The advantages of the LMA over the tracheal tube or facemask: A meta-analysis. Can J Anaesth 1995; 42: 1017-23.

8. Cook TM, Lee G, Nolan JP. The proseal laryngeal mask airway: A review of the literature. Can J Anaesth 2005; 52:739-60.

9. Park C, Bahk JH, Ahn WS, Do SH, Lee $\mathrm{KH}$. The laryngeal mask airway in infants and children. Can $J$ Anaesth 2001; 48:413-7.

10. Wahlen BM, Heinrichs W, Latorre F. Gastric insufflation pressure, air leakage and respiratory mechanics in the use of the laryngeal mask airway (LMA) in children. Paediatr Anaesth 2004; 14:313-7.

11. Ozdamar D, Güvenç BH, Toker K, Solak M, Ekingen G. Comparison of the effect of LMA and ETT on ventilation and intragastric pressure in pediatric laparoscopic procedures. Minerva Anestesiol 2010; 76:592-9.

12. Srivastava A, Longani S, Sinha GK. Comparative study of LMA proseal and tracheal intubation for patients undergoing laparoscopic cholecystectomy in Indian population. J Adv Med Dent Scie Res 2017; 5:73-7.

13. Jamil SN, Alam M, Usmani $H$, Khan MM. A study of the use of laryngeal mask airway (LMA) in children and its comparison with endotracheal intubation. Indian J Anaesth 2009; 53:174-8.

14. Uddin M, Jabbar A, Rahman M, Khan M. Comparison of the LMA-ProSeal and LMA-classic in children. Delta Med $\mathrm{Col} J$ 2018; 6:18-21. 